\title{
Reciclaje de arquitectura vs restauración arquitectónica, ¿herramientas contrapuestas?
}

\author{
Miguel Martínez Monedero*
}

\section{Resumen}

La sensibilización cultural hacia la protección del patrimonio monumental comenzó a desarrollarse a finales del s. XVIII cuando los movimientos ilustrados pusieron de manifiesto el valor de la historia y a los monumentos como testigos mudos de este reconocimiento. Desde entonces hasta hoy la restauración arquitectónica ha seguido un curso pleno de significación y aplicabilidad en el campo de la arquitectura. El reciclaje de arquitectura es en cambio un concepto novedoso. No es que antes no haya habido "reciclaje de arquitectura", es que ha sido en estos últimos años cuando se está comprobando su recurrencia en el momento actual. La concienciación por el consumo de los recursos naturales nos ha llevado a buscar estrategias de sostenibilidad también en la arquitectura. Así hemos encontrado que su "reciclaje", es decir el re-uso de un edificio obsoleto, es una buena estrategia. El reciclaje de arquitectura posee por ello un significado vigente en la actual etapa de crisis del mercado inmobiliario; del mismo modo que la "restauración arquitectónica" fue un concepto recurrente en el s. XIX, cuando nació la sensibilización hacia la conservación de los monumentos y los símbolos nacionales. Este artículo traza un paralelismo entre el desarrollo de la restauración arquitectónica y el reciente "descubrimiento" del reciclaje de arquitectura, estableciendo, a través de la comparación de sus metodologías, un horizonte de desarrollo.

\section{Palabras clave}

Reciclaje arquitectónico; Restauración arquitectónica; Sostenibilidad; Reutilización; Transformación social; Hábitat; Conservación

\section{Abstract: Architectural Recycling vs Architectural Restoration, do competing tools?}

Cultural awareness of the protection of the monuments heritage began to develop at the end of XVIII century when Enlightenment movements were revealed the value of History, and monuments as silent witnesses of this recognition. From then until today, architectural restoration has followed a course full of significance and applicability in the field of architecture. The recycling of architecture on the other hand is a novel concept. It is not that before there has been no "recycling of architecture", it has been in recent years when the current interpretation is being given. The awareness by the consumption of natural resources has led us to also search strategies for sustainability in architecture. We have thus found that "recycling", i.e. the re-use of an obsolete building, it is a good strategy. The recycling of architecture has therefore a current meaning in the current stage of the real estate market crisis; in the same way that the "restoration" was a recurring concept in century XIX, when the awareness towards the conservation of monuments and national symbols was born. This article draws a parallel between the development of architectural restoration and the recent "discovery" of architectural recycling, establishing, through the comparison of their methodologies, a development horizon.

\section{Key words}

Architectural Recycling; Architectural Restoration; Sustainability; Reusing; social transformation; Habitat; Conservation

\section{Recibido: 02/11/2012; aceptado definitivamente: 13/06/2013}

"El presente artículo es fruto de la participación del autor, como investigador a tiempo parcial, en el Proyecto de Investigación de la Universidad de Oviedo, patrocinado por el Ministerio de Ciencia e Innovación, "Restauración y desarrollismo en España. 1959-1975". Referencia: HAR2011-23918, con plazo de ejecución: 01/01/2012 al 31/12/2014. El autor, asimismo, ha sido investigador a tiempo parcial del proyecto de investigación: i+d BIA 2008-02753 "Reciclajes urbanos", de la Universidad de Granada, que se ha desarrollado en los tres años siguientes hasta 2011. Son diversos los resultados de este proyecto y se remite a la bibliografía específica sobre reciclaje de barriadas de vivienda.

"Dr. Arquitecto. Profesor de Proyectos Arquitectónicos de la ETS de Arquitectura de la Universidad de Granada. E-mail: miguel@mmarquitectura.com. 


\section{Restauración arquitectónica}

La sensibilización cultural hacia la protección del patrimonio monumental comenzó a desarrollarse a finales del s. XVIII cuando los movimientos ilustrados pusieron de manifiesto el valor de la historia y a los monumentos como testigos mudos de este reconocimiento (Figura 1). A partir de entonces, la restauración arquitectónica, como hecho cultural propio a la arquitectura, nació unas décadas después. Más concretamente a mediados del s. XIX, cuando la llamada "restauración estilística", enunciada por Viollet-le-Duc, se convirtió en la primera teoría de restauración que, con afán universal, mantenía el propósito de reconocer a esta práctica como una disciplina autónoma y separada de la arquitectura de nueva planta. La restauración, a partir de entonces, dejó de ser un acontecimiento excepcional para erigirse en una actividad profesional sistemática y consolidada, constituyéndose, en pocos años, como una disciplina científica y normativizada con un estatuto teórico propio ${ }^{1}$.

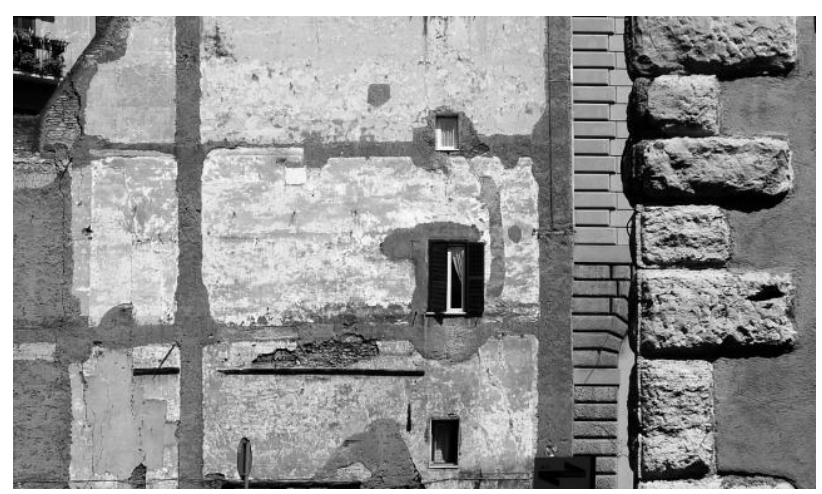

Figura 1. ¿Dónde está el interés patrimonial? En el esquinón de sillería almohadillada, en la esquina renacentista contigua, en el desvencijado testero medianero o en la expresión plástica de su suma. Fuente: Foto cedida por MdLR.

Desde entonces hasta hoy se han sucedido teo-

\footnotetext{
${ }^{1}$ No obstante, es cierto que la teoría estilística enunciada por Viollet-le-Duc supo recoger los distintos criterios que se habían ido produciendo en las décadas anteriores en la conservación de monumentos, y reconvertirlos en una propia teoría, de carácter nacional, pero con afán universal. Este desarrollo normativo se puede consultar, con mucha mayor precisión en González-Varas lbáñez, 1999, p. 145 y ss.
}

rías y metodologías que han seguido ordenadamente a esta primera formulación, pero manteniendo ese mismo propósito diferenciador que enunció en origen Viollet-le-Duc. Todas ellas recogen variedades interpretativas de un mismo hecho cultural: la restauración arquitectónica. El desarrollo y la evolución de este campo han trascendido las estrechas fronteras que en su día lo acotaban y se ha asociado, de manera mucho más amplia, a la conservación de bienes culturales. Su consolidación es tan patente que todos los profesionales que nos dedicamos, de una u otra manera, a este complejo y ancho campo de trabajo reconocemos perfectamente la necesidad de esta disciplina dentro de la arquitectura ${ }^{2}$.

La restauración arquitectónica ha seguido, desde su fundación disciplinar, un recorrido que ha ido acotando su interpretación con el paso de los años. Si en un principio las restauraciones quedaban sometidas al mejor o peor entendimiento de escogidos profesionales, los excesos que se cometieron en aquellos años llevaron, desde muy temprano, a la redacción de normas y procedimientos propios. Las Cartas y normativas, nacionales e internacionales, vinieron a acotar un territorio vasto y ambiguo, en donde la libertad operativa de los proyectistas no se veía lastrada en origen por ningún impedimento.

Gracias a este proceso evolutivo hoy en día la idea que podemos tener de lo que implica la restauración arquitectónica es bastante precisa si atendemos a la cuantiosa producción teórica sobre la especialidad, por más que su entendimiento pueda seguir englobando uno de los usos más populares que se producen en la arquitectura ${ }^{3}$.

\footnotetext{
${ }^{2}$ Creo que sería interesante referir a este respecto dos compendios sobre corrientes de restauración, como son el de Antón González Capitel (1983) y el de Javier Rivera Blanco (1989).

${ }^{3}$ La interpretación popular de la restauración es más diversa ya atendamos a su sentido popular o especializado. $Y$ aun, dentro de éste último ámbito, es utilizado de modo muy distinto tanto en el debate teórico como en la práctica metodológica
} 
Podemos afirmar que la "restauración arquitectónica" designa las operaciones de intervención directa sobre un edificio cuya finalidad es la restitución o la mejora de su comprensión y el restablecimiento de su unidad potencial, que ha sido deteriorada o perdida por un proceso de degradación, y para que el edificio siga existiendo como objeto capaz de provocar una experiencia estética, y siempre que estas operaciones sean posibles sin incurrir en alteraciones o falsificaciones de su naturaleza documental. En este sentido, operaciones características de restauración son la reintegración de faltas, la limpieza de sus materiales constitutivos o la eliminación de elementos añadidos juzgados perjudiciales para la integridad física y la comprensión estética del mismo. Actualmente la crítica sobre restauración desecha, dentro de un entendimiento moderno, las restauraciones "en estilo" pues son falsificadoras del carácter documental del edificio. Las Cartas y la normativa que el debate y la práctica sobre restauración arquitectónica han generado se han centrado especialmente en regular cómo debe procederse, durante el proceso de restauración, con las partes del edificio a conservar y con los elementos a no conservar por no ser suficientemente valorados.

Estas disposiciones tomaron, hace ya tiempo, carácter de legalidad, pues han alumbrado, en el caso de España, la legislación sobre Patrimonio histórico que hemos conocido hasta el momento actual: la Ley republicana de 1933 y la más reciente de $1985^{4}$. Con la promulgación de estas leyes, la restauración arquitectónica, en el ámbito monumental, quedó amparada por principios legales; y con ello, la libertad con la que jugaban los arquitectos en el origen de la disciplina se vio sometida no ya a unas recomendaciones sino a un marco legal propio. La experiencia nos ha

${ }^{4}$ García Fernández, 2007. Sobre la referencia a las normas y leyes en España, ver Morales, 1996. enseñado que si en el desarrollo de nuestras funciones incumplimos este marco normativo, la posible restauración sería literalmente "ilegal". Por eso, la restauración -monumental-, para bien o para mal, se rige por ámbitos normativos y legales, y no está abierta a la interpretación; partiendo de la selección del edificio susceptible de restauración, que mantendrá unos reconocidos valores histórico-artísticos, y siguiendo por la metodología $y$ las herramientas que podemos utilizar ${ }^{5}$.

\section{Reciclaje de arquitectura}

El reciclaje de arquitectura es, al contrario que la restauración arquitectónica, un concepto novedoso que está teniendo un auge importante, debido principalmente a la situación de crisis que el urbanismo actual viene soportando por el agotamiento del modelo especulativo de consumo de suelo (Valero Ramos, 2010, p. 1-11). En términos generales, según su propia definición, reciclar es someter un material usado a un proceso para que se pueda volver a utilizar ${ }^{6}$. Conforme a esto, reciclar arquitectura es realizar ese proceso en un edificio ya usado para que pueda volver a utilizar-

\footnotetext{
${ }^{5}$ Un claro ejemplo de esto lo encontramos en la sentencia que el Tribunal Supremo mantiene para la demolición de la obra de restauración que Giorgio Grassi y Manuel Portacelli realizaron en el teatro romano de Sagunto. En efecto, conforme a la legalidad, esta obra es "ilegal", pero no por ello ha dejado de ser una bella obra de restauración, atenta y sensible al edificio original, y sobre todo a su largo recorrido por la historia. Habría que preguntar, si ello fuera posible, que, cuando pretende revertir el edificio a su estado original, se refiere al que dejó erigido a la sazón el Arquitecto de la 4⿳亠丷厂 Zona Alejandro Ferrant. Pues sabemos que reconstruyó fábricas, acondicionó volúmenes, y redibujó por completo el entendimiento arquitectónico de unas ruinas que se encontraban desdibujadas por años de abandono, expolios y reformas. El proyecto y la obra construida del Teatro Romano de Sagunto puede consultarse en el $n=145$ de la revista Arquitectura del COAM, p. 45-55. El proyecto de Ferrant puede consultarse en: Esteban Chapapría y García Cuetos, 2007.

Según la definición que recoge la Real Academia de la Lengua Española. Por otro lado, "reciclar" forma parte de la terna ecologista de las 3 erres: reducir, reutilizar, reciclar. También conocidas como las tres erres de la ecología o simplemente $3 R$, es una propuesta sobre hábitos de consumo, popularizada por la organización ecologista Greenpeace, que pretende desarrollar hábitos generales responsables como el "consumo responsable". Este concepto hace referencia a estrategias para el manejo de residuos que buscan ser más sostenibles con el medio ambiente y específicamente priorizan la reduc-
} ción de residuos. 
se, conservando o modificando su anterior uso e iniciando de este modo un nuevo ciclo de vida (Chacón Linares, 2008, p. 9 y ss.). El reciclaje es por tanto algo inherente a cada objeto material, y a cada edificio, pues siempre alberga la posibilidad de prolongar su uso. Más aún cuando ese proceso al que aludimos pueda incluir actuaciones de renovación, reforma, rehabilitación o incluso restauración.

No obstante, reciclar arquitectura encierra un significado más amplio que estos otros términos referidos (renovación, reforma...). Términos que, a fin de cuentas, tratan de lo mismo (la recuperación de un objeto material) pero difieren del "reciclaje" de arquitectura en el alcance del proceso y en el objeto sobre el que se actúa, como veremos seguidamente.

"El reciclaje (...) surge de un planteamiento (...) mucho más ambicioso y exigente que la simple rehabilitación entendida de manera convencional. El reciclaje supone iniciar un nuevo ciclo de vida a partir de lo viejo, sin conformarse con meras actuaciones de reparación centradas exclusivamente en solventar problemas inmediatos y aspectos parciales y epidérmicos, ni tampoco embalsamar lo que ya está muerto, como sería prolongar a toda costa situaciones insostenibles, ya sea por el grado de deterioro constructivo-estructural o por un inaceptable planteamiento inicial" (Valero Ramos, 2010, p. 3).

Reciclaje, así entendido, es algo que se ha hecho en la arquitectura desde sus más inmediatos comienzos, al ser un concepto inherente a la amortización por uso de cualquier objeto ${ }^{7}$. En la historia de la arquitectura se han reciclado materiales y edificios buscando siempre prolongar su vida

\footnotetext{
${ }^{7}$ Muchos edificios antiguos de arquitectura "culta" y no "culta" han llegado hasta nuestros días reutilizados para fines diversos. Cómo no recordar el grabado del teatro Marcelo convertido en edificio de viviendas que ya indicaba una práctica que parecía habitual entonces. Así el reciclaje, a lo largo de la historia, se ha apoyado, fundamentalmente, en la lógica del valor de uso, pues un edificio siempre es susceptible de albergar nuevos usos.
}

útil. Los ejemplos, a lo largo de la historia, pueden ser muchos. Me remito, sin ir más lejos, por poner alguno reciente, a los periodos de posguerra del siglo $X X$, en España y en Europa, y a las "recuperaciones" que se dieron en tantos lugares afecta$\operatorname{dos}^{8}$.

Sin embargo ha sido en estos últimos años, desde que se acuñó el término "reciclaje de arquitectura", cuando se le está dando una nueva visión a algo que, como se ha comentado, se ha realizado desde los más inmediatos orígenes de nuestra disciplina ${ }^{9}$. $Y$ es que, en el momento actual, la idea es muy apropiada. El agotamiento del "modelo de negocio" del mercado inmobiliario se une a la concienciación por el excesivo consumo de recursos naturales, generalizado a toda la parte desarrollada del planeta. Esto nos ha llevado a buscar estrategias de bajo consumo y de sostenibilidad en todas las disciplinas, también en la arquitectura. Así hemos encontrado que el "reciclaje" de un edificio obsoleto a través de una actuación capaz de generar un nuevo uso es una estrategia perfectamente enmarcada en el momento actual, por más que haya sido empleada en otros momentos históricos ${ }^{10}$.

Denominar "reciclaje" a un proyecto de arquitectura indica, según se entiende en la definición que podemos encontrar ${ }^{11}$, la voluntad de modificar las posibilidades de funcionamiento de un edificio en una nueva realidad; y pretende, de este modo, buscar nuevos usos en él, pues el anterior había quedado obsoleto o amortizado. El reciclaje es sin duda una estrategia de sostenibilidad, pues aminora el impacto de la arquitectura en nuestro entorno al buscar la reutilización de las infraestructu-

\footnotetext{
${ }^{8}$ Martínez Monedero, 2008a, p. 4-8. Véase también Martínez Monedero, 2008b y 2008c.

${ }^{9}$ Proyecto de investigación: i+d BIA 2008-02753 "Reciclajes urbanos", de la Universidad de Granada.

${ }^{10}$ Sobre la interpretación actual del reciclaje de arquitectura ver Chacón Linares, 2008 y también Chacón Linares y Valero Ramos, 2009, así como González y Sosa, 2009.

${ }^{11}$ Véanse las citas de la nota anterior.
} 
ras existentes y preservar la posible ocupación de nuevos territorios. El mero hecho de considerar el reciclaje sobre la demolición nos lleva a minimizar la "huella" de la arquitectura y a reducir el llamado "espacio basura" (Koolhaas, 2002, p. 6). Se entiende por tanto como una respuesta apropiada que podemos ofrecer al habitual consumo de suelo de la ciudad posmoderna, en donde se otorga prioridad al valor económico en detrimento de otros aspectos de tipo patrimonial, paisajístico o social, como el beneficio comunitario que potencialmente siempre puede aportar la arquitectura. De este modo, frente al conocido ciclo de "consumo de suelo-amortización-abandono" la alternativa del reciclaje, tanto del suelo (de la "huella") como de la arquitectura, plantea una oportunidad que discute, en última instancia, el crecimiento expansivo de la ciudad fomentado principalmente por intereses económicos, propios del mercado capitalista, y cuyos excesos hemos padecido en las últimas décadas ${ }^{12}$

Por eso, reciclar arquitectura, por más que sea un concepto tan antiguo como la propia arquitectura, es plenamente vigente en estos comienzos del s. $X X I$, del mismo modo que la "restauración arquitectónica" fue un concepto recurrente en el s. XIX, cuando nació la sensibilización hacia la conservación de los monumentos y los símbolos nacionales. De este modo podemos trazar un fácil paralelismo: si a finales del s. XIX, esa época neorracionalista dominada por figuras como Viollet-leDuc o John Ruskin, la moda era el reconocimiento de la historia nacional, la puesta en valor de nuestros monumentos y su conservación, ahora la moda es la sensibilización hacia la sostenibilidad del planeta y el ahorro en el consumo de suelo y recursos naturales. Algo que ha sido motivado por el abuso de las décadas pasadas. Y no

\footnotetext{
${ }^{12}$ Sobre lo que implica, desde un punto de vista económico, el reciclaje (rehabilitación) de un edificio respecto a su demolición ver Ramírez de Arellano, 2000.
}

se entienda "moda" como algo peyorativo. En absoluto. Más bien al contrario, la moda es un argumento de contemporaneidad que implica estar actualizado, y como tal la arquitectura no puede ser ajena a ella, pues debe buscar respuestas para cada momento histórico ${ }^{13}$. En este sentido, no podemos decir que la "restauración arquitectónica" esté de moda (aunque sea una materia perfectamente vigente), pero sí, en cambio, el "reciclaje de arquitectura".

\section{Ámbitos de entendimiento}

El reciclaje de arquitectura se desvincula hábilmente del reciclaje de objetos de consumo, pues reconocemos muchas diferencias entre reciclar una botella de vidrio y reciclar un edificio (Chacón Linares y Valero Ramos, 2009, p. 503-510). No es que la arquitectura no sea un "objeto de consumo", la diferencia estriba en el reconocimiento que hacemos, a través de nuestro juicio, del valor que ambos objetos implican para nosotros. La botella no suele adquirir para los usuarios ningún valor emocional (bien es cierto que puede llegar a tenerlo, pero no es lo habitual $)^{14}$. Es un objeto común, estandarizado y fruto de un proceso industrial; aparte de su mejor o peor estética, es normalizado y existen infinitos iguales ${ }^{15}$. Sin embargo con la arquitectura no sucede esto. O por lo menos no debiera suceder. La arquitectura, en cuanto objeto producido por y para la actividad humana, es una manifestación cultural atrapada en la construcción de un lugar concreto, de carác-

\footnotetext{
${ }^{13}$ Sobre la "moda" en la arquitectura consultar en: Sáenz de Oiza, 2007, p. 25 y ss.

${ }^{14}$ En este sentido conviene matizar que si aceptamos que los valores afectivos son emocionales reconoceremos a nuestro alrededor muchos objetos banales cargados de valor emocional. Y también encontraremos objetos industriales con una valoración cultural y simbólica largamente compartida por determinados grupos sociales. En este punto es interesante revisar el concepto de "mercancía cultural" de Max Horkheimer-Theodor Adorno, de la Escuela de Frankfurt.

${ }^{15}$ Otro concepto interesante que viene al caso sería el de "clonación arquitectónica". Éste es abordado con acierto en Hernández Martínez, 2007 y 2008.
} 
ter irrepetible y diferenciada ${ }^{16}$. Esta valoración de la arquitectura como hecho diferencial nos acerca hacia el camino de los bienes culturales. Pues la diferenciación de un edificio sobre el resto, por unos valores reconocibles, es propia de este entendimiento.

La restauración y el reciclaje arquitectónicos se manejan, a fin de cuentas, en dos ámbitos conceptualmente diversos. La restauración, en cuanto a su entendimiento técnico, se inserta en el terreno operativo y nos dirige hacia procedimientos metodológicos, deslizando una interpretación más precisa hacia otros términos próximos pero que matizan su interpretación, como pueden ser la reforma, recomposición, reposición o la rehabilitación ${ }^{17}$. Es decir, la restauración arquitectónica no aborda un planteamiento de uso sobre el objeto restaurado. Si se restaura un objeto material, o un edificio, podemos entender que el uso se mantiene, se modifica, o incluso lo pierde, como sucede con los edificios que son museos de sí mismos. El reciclaje arquitectónico, en cambio, pretende incidir directamente sobre el uso, y no tanto sobre el procedimiento, por más que en un principio pueda parecer lo contrario. Si reciclamos un edificio, como planteamiento de partida, necesitamos actuar sobre él mediante operaciones de rehabilitación, reforma, reconstrucción o incluso restauración, pero el objetivo final es su reutilización y no la restauración en sí misma. Y siguiendo este entendimiento, la restauración arquitectónica se aproxima al concepto de reciclaje cuando incide no sólo sobre la recuperación material del edificio, sino sobre el uso. De manera que podríamos reciclar un edificio, como idea que guíe la planificación de una actuación, y al mismo tiempo

\footnotetext{
${ }^{16}$ Sobre este concepto consultar Moneo, 1988.

${ }^{17}$ Una revisión próxima a la que se propone en este artículo la encontramos en Ramírez de Arellano, 2000, cuando refiere: "Rehabilitar vs. Recuperar" (p. 10-12 y ss.) y aborda la diferenciación de ambos entendimientos y aun otros próximos como restauración, reforma, etc.
}

restaurarlo desde un plano meramente operativo. La restauración, más concretamente la restauración monumental, se apoya siempre en el reconocimiento de ciertos valores que nos inclinan a pensar que deben ser mantenidos, siendo los procedimientos de restauración el vehículo. Estos "valores" serían dos principalmente: el valor documental, de antigüedad, que conocemos como valor histórico; y el valor formal, estético, que conocemos como valor artístico. $\mathrm{Y}$ el reconocimiento solidario de ambos es el paso previo a cualquier planteamiento de restauración sobre un edificio.

Pero de igual modo podemos reconocer que la arquitectura susceptible de reciclaje puede llegar a disponer de estos valores histórico-artísticos, en menor medida, pero que en efecto disponga de ellos. Lo que nos lleva a concluir que lo que motiva que una arquitectura sea considerada como digna de restauración, o susceptible de reciclaje, es, al fin y al cabo, su reconocimiento. Un reconocimiento que puede provenir de su catalogación, como elemento patrimonial, o a través de la objetiva valoración del mismo proyectista, por estar dotada, cualquier obra, de ambos valores y ser considerados dignos de conservación ${ }^{18}$.

\section{Algunos ejemplos}

Para exponer esto de manera más pragmática veamos brevemente un ejemplo de "reciclaje arquitectónico" que la Escuela de Arquitectura de Granada, dentro de su programa oficial de "Proyecto Fin de Carrera", organizó sobre dos barrios obreros de la periferia granadina: el conocido como Caserío de Montijo y el de La Paz-Cartuja (véanse Figuras 2 y 3), ambos próximos físicamente y con múltiples problemas sociales de marginalidad que están provocando un debate sobre su pervivencia o demolición. ¿Cómo pode-

\footnotetext{
${ }^{18}$ Para esta idea, y las que se enuncian en los siguientes párrafos, es interesante ver García Cuetos, 2008.
} 
mos entender el reciclaje sobre estas dos barriadas de la ciudad de Granada? Ambas fueron levantadas en la época desarrollista de los años 70, promovidas por diversos intereses, y con distinta fortuna en su formalización arquitectónica.

"(...) para abordar uno de los principales problemas que habrán de afrontar las ciudades europeas en la próxima década: la obsolescencia de las barriadas residenciales, un fenómeno que nos remite a los polígonos de viviendas sociales que el franquismo construyó entre 1957 (año de la creación del Ministerio de la Vivienda) y 1975. La necesidad de intervención y transformación en estos trozos de ciudad en los que habita un $60 \%$ de la población es obvia y aunque desde hace tiempo se está llevando a cabo proyectos piloto a pequeña o mediana escala resulta patente que va a suponer cada vez más una importante inversión pública" (Valero Ramos, 2010, p. 1-2).

Si atendemos a la consideración de los valores que hacen de la arquitectura un objeto de interés cultural, comprobamos que estas barriadas poseen un valor histórico evidente: son fruto de una promoción de vivienda social, de un momento muy concreto de nuestra historia reciente, de un sistema constructivo, de una ocupación del territorio... Valores históricos perfectamente reconocibles y ponderables. Si atendemos, en cambio, a su valoración artística, comprobamos que estamos ante una arquitectura difícil en su entendimiento pero consecuente con su época, escasa de recursos pero capaz de ofrecer una imagen coherente, reconocible y sensible a muchos factores. Se distinguen en ella ciertos atributos estéticos, espaciales y formales, que atienden por tanto a su consideración artística. Y finalmente, reconocemos también la necesidad que tiene esta barriada de recibir una actuación que revitalice su uso, porque es un espacio degradado. Es evidente que el disfrute de estos espacios queda mermado por su condición semi-arruinada. Quedarían por considerar los aspectos de naturaleza social, no menos importantes que los anteriores, que brevemente se resumen en que ambas barriadas son residencia de poblaciones marginales, generalmente inmigrantes norteafricanos que han ido acomodándose en estos inmuebles.

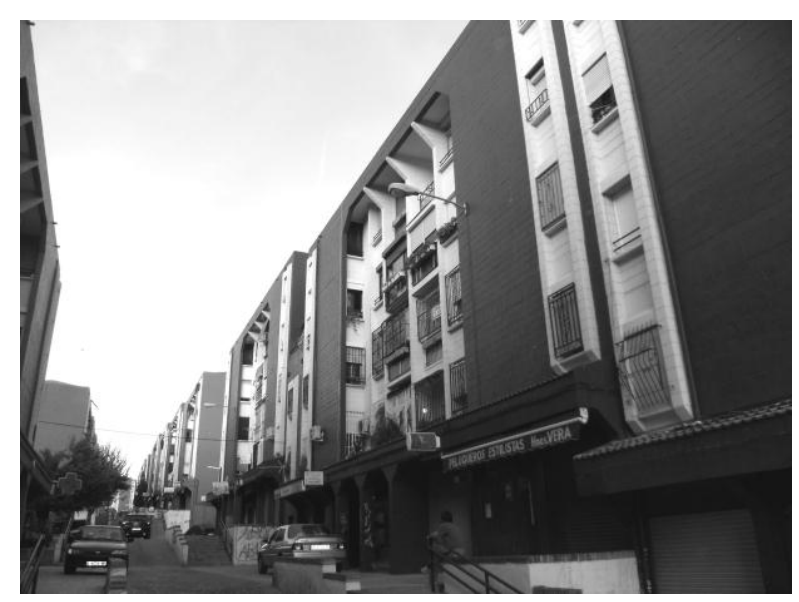

Figura 2. Viviendas en bloque adosado del popular barrio granadino de Caserio de Montijo, 2010. Fuente: Foto del autor.

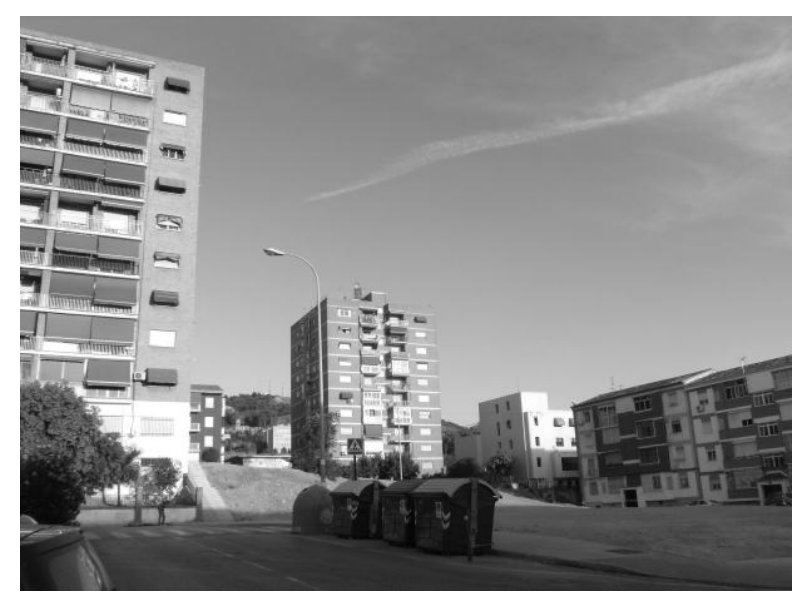

Figura 3. . Viviendas en bloque aislado del popular barrio de La Paz-Cartuja, "Torres Osuna", 2010. Fuente: Foto del autor.

Al margen del aspecto social, la consideración de esta arquitectura como poseedora de valores histórico-artísticos, por sí solos, encaminarían una posible actuación de reciclaje al territorio de la restauración y, por tanto, propia a sus herramientas. No obstante, es fácil entender que no sería coherente plantear una actuación de rehabilitación entendida en claves de "restauración". Nos faltarían, sin duda, el reconocimiento previo de los valores ya comentados (histórico-artísticos) y 
seguramente una posible catalogación. Así deslizamos conscientemente la intervención sobre el territorio del "reciclaje", sin acercarnos a la "restauración", por entender que estos edificios no merecen este tipo de protección.

Una vez situado el proyecto en el ámbito del reciclaje arquitectónico, como proyectistas tendremos la facultad de actuar con cierta libertad operativa, sujeta obviamente al cumplimiento de una normativa urbanística que, en caso de promociones de vivienda social de ámbito periférico al centro histórico, permitiría, dentro de las condiciones de aprovechamiento urbanístico, "hacer lo que quisiéramos". Esto incluye la revisión formal del objeto de reciclaje, aún más, la revisión integral, lo que afectaría a su realidad constructiva, estructural, volumétrica, espacial, etc. Esta revisión nos llevaría a conseguir un nuevo edificio que, si bien tendría una referencia obligada al existente (mantendría algunos sistemas constructivos), resignificaría por completo su entendimiento arquitectónico. La sensibilidad del proyectista podría indicar la posibilidad cierta de conservar elementos o sistemas constructivos suficientes para que la lectura de esas arquitecturas fuese consecuente con su pasado histórico. Es decir, ser sensibles con el valor documental y artístico que estas barriadas atesoran, pues ciertamente los tienen. Así el posible proyecto de reciclaje sobre estas barriadas debería ser sensible a estos valores y al mismo tiempo aportar una propuesta arquitectónica que consiguiera su actualización y mejora, por medio de su completa revisión.

$\mathrm{Si}$ vamos, en este momento de nuestro argumento, a la disciplina de la restauración, podríamos preguntarnos, ¿no contempla la actitud "crítica" la posibilidad de modificación de la realidad formal del objeto? (Brandi, 1988). Y es que esta corriente afirma que la restauración es un acto crítico y creativo. Crítico por cuanto es capaz de reconocer unos valores que deben perdurar en el objeto sometido a restauración, y creativo por cuanto es capaz de aportar una nueva propuesta estética que integra la lectura antigua con una nueva lectura moderna, proveniente de una nueva materialidad (Brandi, reed. 1993, p. 52). Así podríamos entender nuestra actuación de reciclaje como un proceso "crítico" sobre unos edificios no reconocidos como elementos de interés patrimonial, pero poseedoras de unos valores con respecto a los que, como arquitectos, tenemos la obligación de ser sensibles.

Para reforzar esta discusión, desde un punto de vista meramente metodológico, si atendemos a las herramientas que pone en marcha un proyecto de arquitectura, el reciclaje que pudiéramos hacer con este ejemplo encontraría prácticamente las mismas herramientas operativas que las que podríamos en juego si la actuación fuera en cambio de restauración. Hagamos un repaso rápido de estos:

- Toma de datos previos a la realización de una propuesta. Estudio profundo del edificio existente, estudio histórico, aspectos sociales de la barriada, estudio del medio, topografía, geografía, geología.... Es decir, conocer sobre qué vamos a actuar.

- Juicio crítico del edificio. Estudio arquitectónico, compositivo, formal, etc., conducente al reconocimiento de sus valores tangibles e intangibles (importancia emocional que estos edificios puedan significar sobre una población que ha cursado su vida en ellos).

- Estudio funcional del edificio.

- Estudio de la repercusión social de la actuación.

- Estudio de su implantación y condicionantes urbanos, de sus relaciones espaciales y volumétricas en su contexto.

- Estudio de su realidad constructiva, patologías, vicios, etc., que sirvan como base para dirigir las actuaciones de consolidación y/o refuerzo de sus sistemas constructivos- 
estructurales constitutivos.

- Y por último, propuesta arquitectónica que considere todos los valores anteriores y sea capaz de condensarlos, manipularlos, y rehacerlos a través de un proyecto de arquitectura. Aquí se incluyen estrategias de eliminación, adición, manipulación y transformación de la realidad de ese edificio conforme a estas distintas vicisitudes.

Reconocemos, por tanto, que estas herramientas de reciclaje no son tan divergentes de las que pudieran regir un proyecto de restauración. Por tanto, ¿qué es lo que realmente diferencia un proceso del otro? Ambas actuaciones deben quedar recogidas dentro de ciertos límites amparados por distintos argumentos. Si en el reciclaje de arquitectura los límites quedan marcados por la mayor o menor sensibilidad del proyectista, la restauración arquitectónica queda amparada por la cuantiosa normativa sobre restauración de que disponemos como técnicos.; y no sólo normativa, sino leyes. $Y$ es que demoler un edificio no protegido pero susceptible de reciclaje no es punible, por más interesante que éste sea. Cuántos edificios no catalogados como patrimonio han corrido esta suerte, cuánta buena arquitectura perdida por no encontrar a tiempo un reciclaje apropiado, sensible a los valores del edificio y hábil en incorporar un nuevo uso a algo obsoleto ${ }^{19}$. La breve experiencia acumulada en estos trabajos académicos, durante los últimos años, nos lleva a afirmar que, en efecto, el proyecto de reciclaje realiza una valoración del edificio no sometida a ningún parámetro externo más que el propio juicio y sensibilidad del arquitecto, pues el objeto susceptible de reciclaje no queda amparado por ninguna normativa ni protección alguna.

Además de los ya referidos ejemplos de los ba-

\footnotetext{
${ }^{19}$ Sólo comentar un ejemplo reciente que aún escuece nuestra conciencia: la "Pagoda" de Miguel Fisac en Madrid, demolido para levantar en su lugar una nueva construcción.
}

rrios Caserío de Montijo y La Paz-Cartuja, se han estudiado también otros casos como los conocidos secaderos de tabaco de la Vega granadina (Figura 4), o diversas edificaciones industriales de finales del s. XIX, hoy obsoletas, como azucareras, almazaras, molinos, etc. (véase el antiguo Matadero de Madrid en Figura 5), encontrándonos edificios pobres de construcción pero cargados de significado y valores arquitectónicos. Todos se encuentran también en esa delicada coyuntura por la cual, a falta de un uso viable, envejecen anónimos a la espera de una posible demolición o, quién sabe, una deseable actuación revitalizadora a través de su cambio de uso y puesta en valor $^{20}$. Esto nos lleva a pensar que hay mucha arquitectura esperando actuaciones de este tipo, deseosa de encontrar una solución viable antes de concluir que su demolición y la construcción de nueva planta sean la única salida.

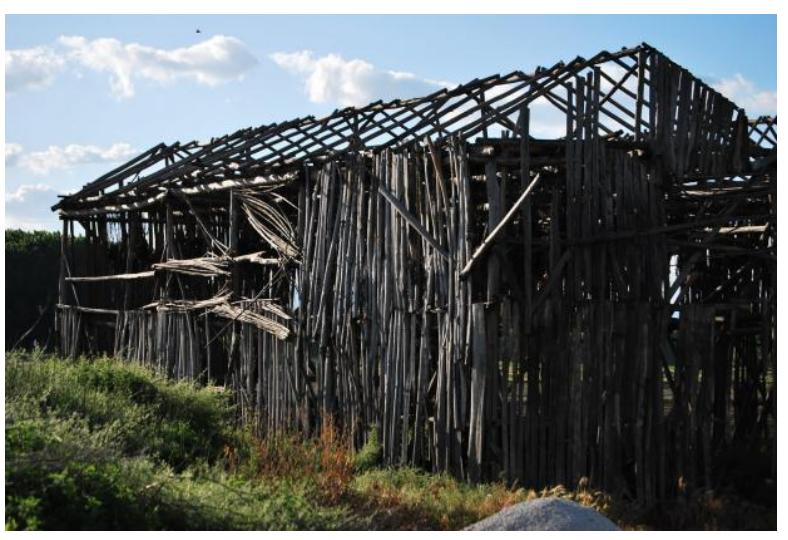

Figura 4. Secadero de tabaco de la Vega de Granada. Su evidente interés patrimonial está en riesgo. Fuente: Foto del autor.

Entendemos que ciertos edificios mantienen una visible potencialidad de reciclaje. Sería un hecho positivo reconocer en ellos estos valores,

\footnotetext{
${ }^{20} \mathrm{~A}$ otra escala, otro tema de investigación, propuesto como tema oficial de PTS, aborda el actual recinto ferial de Armilla, en el conocimiento de que sus construcciones, de contrastado valor arquitectónico pero no protegidas por ningún instrumento, ven un futuro incierto, amenazadas por el derribo si no se encuentra una solución viable a su uso. Encontramos edificios de más de 100 años de antigüedad, con un indudable valor patrimonial, pero no reconocidos, que corren peligro de demolición. Es nuestra responsabilidad, como agentes partícipes en estos procesos, aportar las herramientas necesarias para conseguir su posible reciclaje y pervivencia
} 
denunciarlos y, si es posible, protegerlos. Estos ejemplos son reconocibles y su catalogación, por estos argumentos, no implicaría grandes esfuerzos. Su pérdida sería siempre un hecho lamentable. Su posible catalogación denunciaría estos valores (histórico-artísticos, funcionales, sociales, paisajísticos...), pero sobre todo sería capaz de reconocer su evidente potencialidad de albergar un nuevo uso sobre el anterior, ya obsoleto.

De este modo el reciclaje de arquitectura no se quedaría meramente en una denominación terminológica, más o menos "modista", sino que iría efectivamente a constituirse, a través de las políticas urbanísticas apropiadas, como una posibilidad cierta, materializada en algún tipo de protección, o control sobre algunos edificios, y que dificultase la impunidad que existe actualmente para su demolición. Así el reciclaje de arquitectura llegaría a atesorar ese carácter innovador, que la propia invención del término parece reclamar, y sería un factor diferencial sobre lo que la historia de la arquitectura nos ha mostrado como "reciclaje". Serviría, en efecto, para el control de las prácticas que se podrían llevar a cabo sobre esos edificios, o incluso sobre los agentes que pudieran intervenir en el proceso. E intentaría evitar la impunidad de una demolición justificada solamente por el agotamiento de su uso actual, por la inexistencia de una catalogación -patrimonial o de otro tipo- o por criterios meramente económicos. Esta catalogación, por último, no debería incidir sobre las posibilidades que tenemos de actuación sobre él, como sucede con la restauración arquitectónica (la abrumadora profusión de normas, reglamentos, cartas y leyes debieran servirnos de enseñanza), y seguir manteniendo la libre interpretación del proyectista en el desarrollo del proyecto de reciclaje.

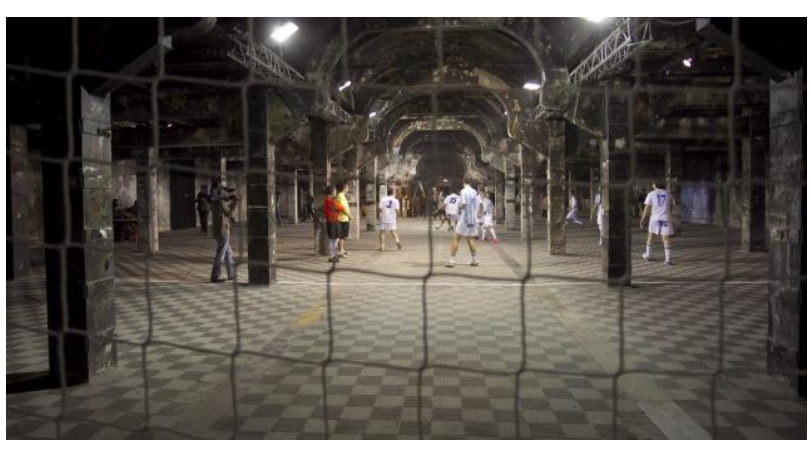

Figura 5. Jugando al futbol en el antiguo Matadero de Madrid, hoy reconvertido en centro de actividades lúdico-culturales. Fuente: Foto del autor.

\section{Referencias}

BRANDI, Cesare. Teoría de la restauración. Madrid: Alianza Forma, 1988 (reed. 1993).

CHACÓN LINARES, Eva. Software de reciclaje. Aproximación al diseño de programas para la transformación de la vivienda social. Universidad de Granada, ETS de Arquitectura. Trabajo de investigación tutelado. Inédito, 2008.

CHACÓN LINARES, Eva y VALERO RAMOS, Elisa: Crecer por dentro. Estrategias de reciclaje urbano para el tercer milenio. En Hibridación y transculturalidad en los modos de habitación contemporánea. El territorio andaluz como matriz receptiva. Actas de los Seminarios de apoyo a la investigación de la Universidad de Sevilla. Sevilla: Servicio de Medios Audiovisuales (SAV) de la Universidad de Sevilla, 2009.

ESTEBAN CHAPAPRÍA, Julián y GARCÍA CUETOS, Mํㅡㄹ Pilar. Alejandro Ferrant y la conservación monumental en España (1929-1939). Castilla y León y la primera zona monumental. (2 Volúmenes). Valladolid: Junta de Castilla y León, 2007.

GARCÍA CUETOS, Mํㅗㄹ. Pilar. Entre el anticuarismo y la sostenibilidad. Una reflexión sobre desrestauración y materia. En III Bienal de Restauración Monumental. Sobre la Des-restauración. Sevilla: Instituto Andaluz del Patrimonio, 2008. GARCÍA FERNÁNDEZ, Javier. La regulación y la gestión del Patrimonio Histórico-Artístico durante la Segunda República (1931-1939). e-rph. 
Revista electrónica de patrimonio histórico, 꾼 1, diciembre 2007.

<http://www.revistadepatrimonio.es/revistas/nume ro1/legislacion/estudios/articulo.php>. (Consultado el 4 de septiembre de 2013).

GONZÁLEZ, Magüi y SOSA, José Antonio (Nred arquitectos). Reciclar, más que rehabilitar o reconstruir. Reciclar es: iniciar un nuevo ciclo a partir de lo viejo. Reconstruir: volver a construir lo que ya existió. Rehabilitar: habilitar una construcción decadente. Catálogo de la exposición, 2009.

GONZÁLEZ CAPITEL, Antón. El tapiz de Penélope. Apuntes sobre las ideas de restauración e intervención arquitectónica. Arquitectura, 1983, no 244, p. 24-34.

GONZÁLEZ-VARAS IBÁÑEZ, Ignacio. Conservación de bienes culturales, teoría historia y principios. Madrid: Cátedra, 1999.

HERNÁNDEZ MARTíNEZ, Ascensión. La clonación arquitectónica. Madrid: Siruela, 2007.

HERNÁNDEZ MARTíNEZ, Ascensión. De clones y otros monumentos. Clío: Revista de Historia, 2008, no 79, p. 20-23.

KOOLHAAS, Rem. Espacio Basura. Barcelona: Gustavo Gili, 2002.

MARTÍNEZ MONEDERO, Miguel. Proyectar el vacío, la reconstrucción arquitectónica de Múnich y Berlín tras la Segunda Guerra Mundial. Granada: Secretariado de Publicaciones de la Universidad de Granada. Biblioteca de Arquitectura y Restauración, 2008a.

MARTÍNEZ MONEDERO, Miguel. La reconstrucción de Berlín, la búsqueda de una nueva identidad. Loggia: Arquitectura y restauración, 2008b, ํㅡㄹ 21, 26-37.

MARTÍNEZ MONEDERO, Miguel. La reconstrucción de Múnich, tradición y renovación. Loggia: Arquitectura y restauración, 2008c, ํㅡㄴ 21, p. 3851.

MONEO, Rafael. El lenguaje de la inmovilidad substancial. Madrid: Circo, 1988.

MORALES, Alfredo J. Patrimonio históricoartístico. Madrid: Ed. Historia 16, 1996.

RAMÍREZ DE ARELLANO, Antonio. Aspectos Económicos de la Recuperación de Edificios. Sevilla: Instituto Universitario de Ciencias de la Construcción. Universidad de Sevilla, Escuela Técnica Superior de Arquitectura. Textos de Doctorando, Serie: Arquitectura, № 112, 2000.

RIVERA BLANCO, Javier. Teoría e historia de la intervención en monumentos españoles hasta el Romanticismo. Valladolid. Discurso de ingreso en la Real Academia de Bellas Artes de La Purísima Concepción de Valladolid, 1989.

SÁENZ DE OIZA, Francisco Javier. Escritos y conversaciones. Madrid: Fundación Caja de Arquitectos, Colección La cimbra nº 3, 2007.

VALERO RAMOS, Elisa. Reciclaje de polígonos residenciales, una alternativa sostenible. SB10mad. Sustainable building conference. Sevilla, 2010, inédito.

\section{Cita del artículo}

MARTÍNEZ MONEDERO, M. Reciclaje de arquitectura vs restauración arquitectónica, ¿herramientas contrapuestas? Hábitat y Sociedad, 2012, 끄 5, p. 23-33. $<$ www.habitatysociedad.us.es $>$.

http://dx.doi.org/10.12795/HabitatySociedad.2012.i5.03 